\title{
Effects of Geometry Design Parameters on the Static Strength and Dynamics for Spiral Bevel Gear
}

\author{
Zhiheng Feng ${ }^{1}$ and Chaosheng Song ${ }^{2}$ \\ ${ }^{1}$ Guangxi Liugong Machinery Co., Ltd, Liuzhou, Guangxi 545007, China \\ ${ }^{2}$ The State Key Laboratory of Mechanical Transmissions, Chongqing University, Chongqing 400030, China \\ Correspondence should be addressed to Chaosheng Song; chaoshengsong@hotmail.com
}

Received 15 April 2017; Revised 17 June 2017; Accepted 3 July 2017; Published 31 July 2017

Academic Editor: Paolo Pennacchi

Copyright (c) 2017 Zhiheng Feng and Chaosheng Song. This is an open access article distributed under the Creative Commons Attribution License, which permits unrestricted use, distribution, and reproduction in any medium, provided the original work is properly cited.

\begin{abstract}
Considering the geometry design parameters, a quasi-static mesh model of spiral bevel gears was established and the mesh characteristics were computed. Considering the time-varying effects of mesh points, mesh force, line-of-action vector, mesh stiffness, transmission error, friction force direction, and friction coefficient, a nonlinear lumped parameter dynamic model was developed for the spiral bevel gear pair. Based on the mesh model and the nonlinear dynamic model, the effects of main geometry parameters on the contact and bending strength were analyzed. Also, the effects on the dynamic mesh force and dynamic transmission error were investigated. Results show that higher value for the pressure angle, root fillet radius, and the ratio of tooth thickness tend to improve the contact and bending strength and to reduce the risk of tooth fracture. Improved gears have a better vibration performance in the targeted frequency range. Finally, bench tests for both types of spiral bevel gears were performed. Results show that the main failure mode is the tooth fracture and the life was increased a lot for the spiral bevel gears with improved geometry parameters compared to the original design.
\end{abstract}

\section{Introduction}

As a key component of drive axles, the failure of spiral bevel gears is detrimental to the performance and quality of the driveline system. Therefore, understanding the influence of design parameters, such as pressure angle, helix angle, root fillet radius, and tooth thickness ratio, on gear performance, is essential and can be applied to improve the dynamic performance of spiral bevel gears. This investigation is undertaken because prior studies on effects of spiral bevel gear design parameters on driveline dynamics are not widely seen in the open literature. Zhao and Dong [1] proposed that gears having $28^{\circ}$ pressure angle have better contact and bending strength than those with $20^{\circ}$ pressure angle. Huang et al. [2] determined that gears of bigger pressure angle have better lubrication performance than those with nominal $20^{\circ}$ pressure angle based on elastohydrodynamic lubrication theory.

Previously, there have been extensive studies performed on static strength and dynamics for spiral bevel and hypoid gears. Fan [3,4] described a method of determining an optimized face cone element for spiral bevel and hypoid gears based on the incorporation of calculation of tooth surface and root geometries, the conjugate relationship of the mating gear members, the ease-off topography, and the tooth contact analysis. Also, he proposed a method of correcting tooth surface errors for spiral bevel and hypoid gears generated by the face-hobbing process using computer numerically controlled hypoid gear generators. Kahraman $[5,6]$ proposed an accurate and practical methodology based on ease-off topography to perform loaded tooth contact analysis of spiral bevel and hypoid gears having both types of local and global deviations. Also, he investigated the impact of misalignments on root stresses of hypoid gear sets experimentally and theoretically. Yang et al. [7] proposed a pinion development approach in order to obtain excellent transmission performance of the face-milled spiral bevel and hypoid gears. Kawasaki et al. [8] proposed a method for remanufacturing pinion member of large-sized skew bevel gears using a CNC machining center and respecting an existing gear member. 

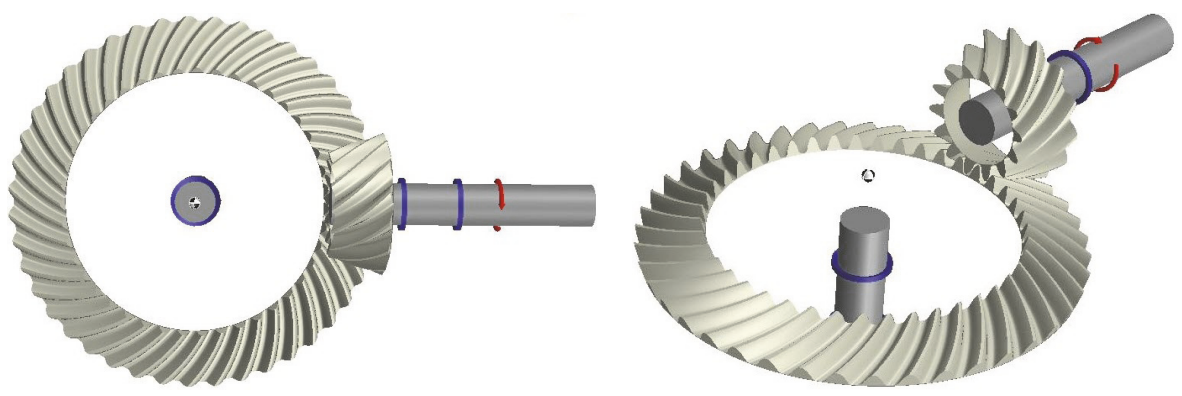

FIGURE 1: Mesh model of the spiral bevel gear pair.

The gear geometry and kinematics of space curve meshing were investigated and the mathematical model of conicalhelix bevel gears from the idea of logarithmic spiral bevel gears was proposed [9]. Simon [10,11] presented a method for the determination of optimal tooth modifications in spiral bevel gears based on improved load distribution and reduced maximum tooth contact pressure and transmission errors. Also, he proposed an optimization methodology to systematically define the optimal head-cutter geometry and machine-tool settings to simultaneously minimize the tooth contact pressure and angular displacement error of the driven gear and to reduce the sensitivity of face-hobbed spiral bevel gears to the misalignments. Yang and Lim [12] developed a multicoordinate dynamic model of a hypoid geared rotor system considering the propeller shaft bending effect. Peng [13] developed the multibody dynamic model for hypoid gear pair and investigated the effects of misalignments, torque loads, and eccentricity on the dynamic responses. Most of the research efforts on the optimization and comparison of the design parameters of spiral bevel gears are mainly based on the static strength analysis. Those studies ignored the influences on the dynamic characteristics that directly control the vibration, shock, and noise responses of running gears. Furthermore, there are even fewer studies considering the influence of the lubricating oil film. When the lubricating oil film effect is examined, most previous models assumed full film lubrication, which is not always true in practice because there is often not enough oil to create a full film contact condition. In most situations, spiral bevel gears operate in a condition of mixed lubrication with both full film and asperity contacts. This, of course, affects the static mesh and dynamics. Hence, a more realistic analysis of the friction characteristics that accurately describe the influence of friction force and friction coefficient on the dynamics of spiral bevel gears is critically needed.

Accordingly, the goals of this study are given as follows: (1) study the effects of the design parameters of spiral bevel gears on tooth bending strength and dynamics; (2) develop a nonlinear lumped parameter dynamic model considering the effect of the friction; (3) build a tooth mesh friction coefficient model for the mixed lubrication condition; (4) compare and analyze the dynamic responses of improved gears to original gears; (5) verify the computational results by comparing to the bench test results.
TABLE 1: Gearing design parameters.

\begin{tabular}{lcccc}
\hline & $\begin{array}{c}\text { Pressure } \\
\text { angle }\left(^{\circ}\right)\end{array}$ & $\begin{array}{c}\text { Tooth } \\
\text { thickness } \\
\text { ratio }\end{array}$ & \multicolumn{2}{c}{$\begin{array}{c}\text { Root fillet radius } \\
(\mathrm{mm})\end{array}$} \\
\hline Original & 20 & 2.09 & 1.5 & Pinion \\
Optimized & 22.5 & 2.21 & 1.9 & Wheel \\
\hline
\end{tabular}

\section{Geometry Design and Strength Analysis}

A set of spiral bevel gears with a high rate of failure were considered in this study. The weakness of these gears was found to be the poor tooth bending strength. An improved set of design parameters with optimized pressure angle, tooth thickness ratio, and tooth root fillet were determined. First, instead of $20^{\circ}$ pressure angle, $22.5^{\circ}$ pressure angle was applied to increase the bending strength. In fact, bevel gears with larger pressure angle are commonly used in heavy duty applications. Then, the tooth root fillet radius that is known to play an important role in gear performance was increased to reduce the tooth root stress concentration. The value of tooth root fillet radius depends on the fillet radius of the blade tip. There are many considerations for choosing the maximum blade tip fillet radius: avoidance of gear interference while running, manufacturability of the blade tip fillet, and scuffing prevention of the tooth flank due to the nonworking face of the blade using a commercial gear cutter; the cutter parameters can be chosen to achieve the desired gear parameters. Also, the cutter offset can be adjusted to obtain the specified tooth thickness ratio. The original and improved design parameters are listed in Table 1.

Based on the geometry design parameters, a commercial software Romax was used to create the mesh model and perform the loaded tooth contact analysis for the spiral bevel gear pair with the original and optimized parameters. The mesh model is shown in Figure 1 . And the load condition with $4895 \mathrm{Nm}$ as the input torque and $200 \mathrm{Rpm}$ as the input speed was used for the subsequent calculations. Then the mesh stiffness, transmission error, line-of-action, equivalent mesh radius, and other mesh parameters can be calculated [14] as the input for the subsequent dynamic model.

The calculated results for the contact strength and bending strength are shown in Table 2 for the original spiral 
TABLE 2: Contact and bending stress and safety factor of original spiral bevel gears.

\begin{tabular}{lcc}
\hline & Pinion & Wheel \\
\hline Number of gear meshes & 1 & 1 \\
Life factor at contact stress & 1.432 & 1.432 \\
Working stress $s_{\_} w$ (contact) $(\mathrm{MPa})$ & 2628 & 2882 \\
Contact stress $s_{-} c$ (contact) $(\mathrm{MPa})$ & \multicolumn{2}{c}{2734.53} \\
Safety factor (contact) & 0.96 & 1.05 \\
Life factor at bending stress & 0.91 & 1.21 \\
Working stress $s_{-} w$ (bending) $(\mathrm{MPa})$ & 535.8 & 610.9 \\
Bending stress $s_{-} c$ (bending) $(\mathrm{MPa})$ & 470.7 & 628.1 \\
Safety factor $($ bending) & 1.14 & 0.97 \\
\hline
\end{tabular}

TABLE 3: Contact and bending stress and safety factor of optimized spiral bevel gears.

\begin{tabular}{lcc}
\hline & Pinion & Wheel \\
\hline Number of gear meshes & 1 & 1 \\
Life factor at contact stress & 1.364 & 1.364 \\
Working stress $s_{-} w$ (contact) $(\mathrm{MPa})$ & 2674 & 2912. \\
Contact stress $s_{-} c$ (contact) $(\mathrm{MPa})$ & \multicolumn{2}{c}{2604.47} \\
Safety factor (contact) & 1.027 & 1.118 \\
Life factor at bending stress & 0.81 & 0.95 \\
Working stress $s_{-} w$ (bending) $(\mathrm{MPa})$ & 538.54 & 623.1 \\
Bending stress $s_{-} c$ (bending) $(\mathrm{MPa})$ & 420.34 & 494.28 \\
Safety factor (bending) & 1.281 & 1.261 \\
\hline
\end{tabular}

bevel gears. It can be observed that the contact stress of original spiral bevel gears is $2734.53 \mathrm{MPa}$. The bending stress is $470.67 \mathrm{MPa}$ for pinion and $628.10 \mathrm{MPa}$ for wheel. The contact safety factor of pinion is 0.96 , which indicates high risk of surface pitting. This can be avoided by using shot peening in tooth surface to intensify the contact strength. Also, the bending safety factor of the wheel is relatively low, which may lead to tooth fracture.

The calculated results for the improved spiral bevel gears are shown in Table 3. The contact stress is $2604.47 \mathrm{MPa}$, which has been reduced by $4.76 \%$ as compared to the performance of the original gears. Bending stress is $420.34 \mathrm{MPa}$ for pinion and 494.28 MPa for wheel, which represent a decrease of $10.69 \%$ and $21.31 \%$, respectively. Contact and bending safety factors also increased. From the results shown in the tables, it can be concluded that the gears with $22.5^{\circ}$ pressure angle have a relatively lower contact and bending stress level compared to the $20^{\circ}$ pressure angle gears. The bending stress of wheel shows a significant reduction. The lower bending stress will improve the fatigue life of the spiral bevel gear.

\section{Dynamic Modelling Considering Mixed Elastohydrodynamic Lubrication}

3.1. Dynamic Model. Spiral bevel gear has very complex tooth geometries and kinematics. Unlike spur and helical gears, the mesh point, mesh force, and line-of-action vector for spiral bevel gear are time-varying in the 3-dimensional space. These spatial mesh characteristics along with time-varying transmission error and mesh stiffness are the primary cause of gear vibration and noise. To tackle the gear vibration problem, a nonlinear time-varying lumped parameter dynamic model is proposed as shown in Figure 2, which considers time-varying effects of mesh point, mesh force, line-of-action vector, mesh stiffness, transmission error, friction force direction, and friction coefficient as the result of varying contact areas at different roll angles $[15,16]$. Note that the time-variation behavior also occurs even under constant gear speed.

In this dynamic model, the pinion and wheel are both defined as rigid bodies with complete degrees of translation and rotation freedom. The driver and load have one degree of rotational freedom each and are connected to the pinion and wheel through a set of torsional stiffness element. Gears are supported by a set of infinitesimal lumped stiffness and damping elements as the equivalent structure of shafts, bearings, and housing. In addition to the direction of the friction force as the parametric excitation parameter, the kinematic transmission error excitation and backlash nonlinearity are also included as described earlier.

The resultant 14 degrees of freedom dynamic equation can be written as

$$
[M]\{\ddot{q}\}+[C]\{\dot{q}\}+[K]\{q\}=[F],
$$

where $[M]$ is the lumped mass matrix, as

$$
\begin{gathered}
{[M]=\operatorname{diag}\left[I_{D}, M_{p x}, M_{p y}, M_{p z}, I_{p x}, I_{p y}, I_{p z}, M_{g x}, M_{g y},\right.} \\
\left.M_{g z}, I_{g x}, I_{g y}, I_{g z}, I_{L}\right],
\end{gathered}
$$

where $[q]$ is the generalized coordinates matrix, as

$$
\begin{aligned}
& {[q]=\operatorname{diag}\left[\theta_{D}, x_{p}, y_{p}, z_{p}, \theta_{p x}, \theta_{p y}, \theta_{p z}, x_{g}, y_{g}, z_{g}, \theta_{g x}, \theta_{g y},\right.} \\
& \left.\theta_{g z}, \theta_{L}\right] .
\end{aligned}
$$

And where $[F]$ is force and friction force and it can be represented by

$$
[F]=\left\{T_{D}, h_{p} F_{m}-g_{p} F_{m f},-h_{g} F_{m}+g_{g} F_{m f}-T_{L}\right\}^{T},
$$

where $I_{D}$ and $I_{L}$ are mass moments of inertias of driver and load and $I_{l i}$ is the mass moment of inertia about the axis $l i$ in the coordinate system $S_{l}(i=x, y, z ; l=p, g$ for pinion and wheel, resp.). Furthermore, $[K]$ and $[C]$ are the stiffness and damping matrices of shafts and bearings. The damping matrix $[C]$ is assumed to be proportional viscous type representing the dissipation of energy due at the gear mesh and shaftbearing components. Here, $T_{D}$ and $T_{L}$ are the torques applied to the engine and load, respectively. $h_{l}$ and $g_{l}(l=p, g)$ are the directional transformation vectors.

The dynamic transmission error can be given by

$$
\delta=\left\{h_{p}\right\}\left\{q_{p}\right\}-\left\{h_{g}\right\}\left\{q_{g}\right\} .
$$




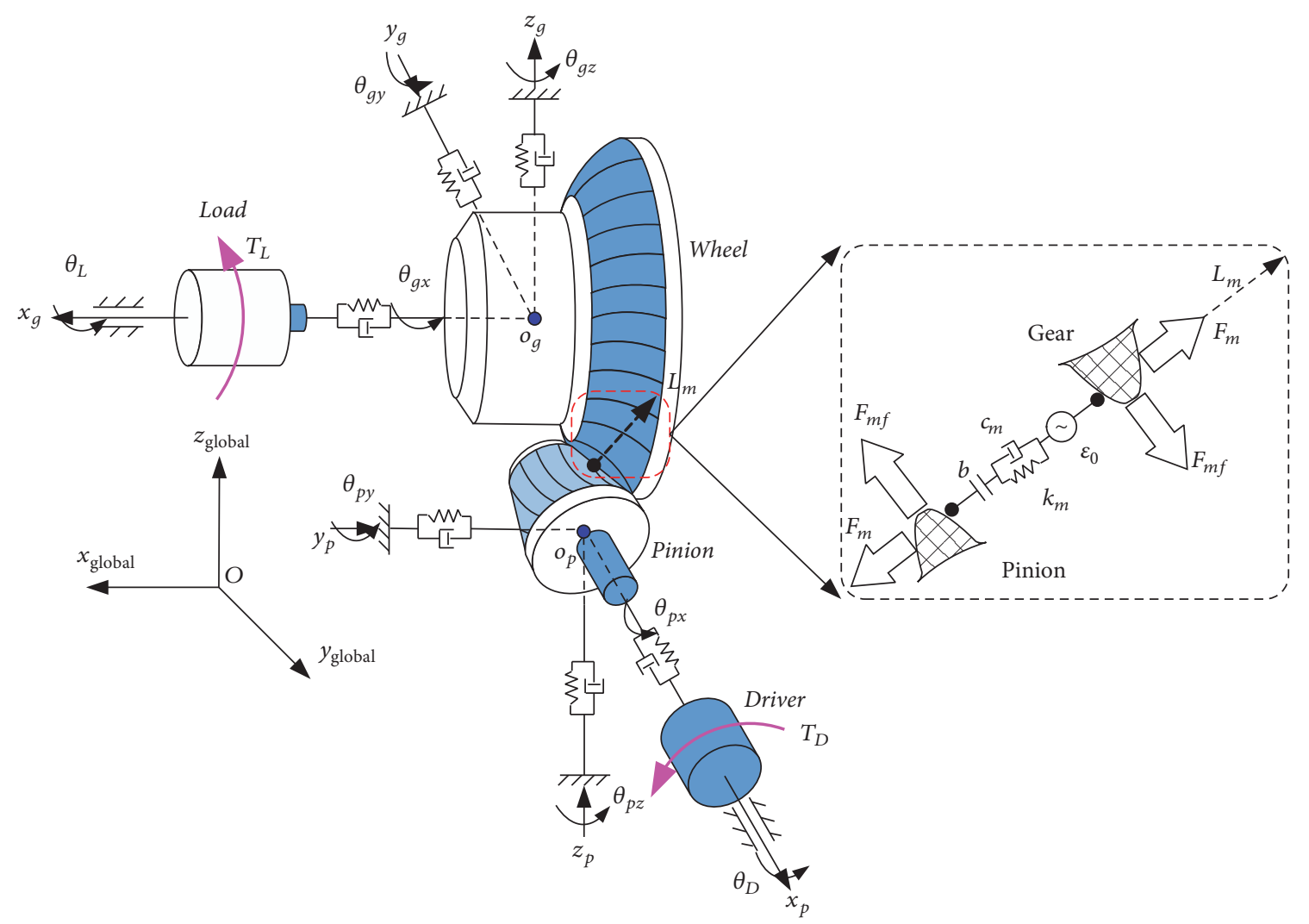

FIGURE 2: The dynamic model for spiral bevel gears.

The dynamic mesh force can be given by

$$
F_{m}= \begin{cases}k_{m}(\delta-e-b)+c_{m}(\dot{\delta}-\dot{e}), & \delta-e>b \\ 0, & -b<\delta-e<b \\ k_{m}(\delta-e+b)+c_{m}(\dot{\delta}-\dot{e}), & \delta-e<b,\end{cases}
$$

where $e$ is the static transmission error and $b$ is the gear backlash. $k_{m}$ and $c_{m}$ are the mesh stiffness and damping element at the mesh point with the direction along the lineof-action. The mesh damping is shown as

$$
c_{m}=2 \xi_{g} \sqrt{\frac{k_{\mathrm{am}} I_{p z} I_{g z} \lambda_{g z}^{2} \lambda_{p z}^{2}}{\lambda_{g z}^{2} I_{g z}+\lambda_{p z}^{2} I_{p z}}}
$$

where $\xi_{g}$ is the mesh damping ratio, $k_{\mathrm{am}}$ is the average mesh stiffness, and $\lambda_{l z}(l=p, g)$ is the projection of line-of-action along the tangential direction of rotational motion.

The dynamic friction force is written as

$$
F_{f m}=\mu F_{m}
$$

where $\mu$ is the friction coefficient.

3.2. Friction Model. Spiral bevel gears are typically operating in a condition consisting of full film and asperity contacts. In this state, the tooth contact area is divided into two situations.
The first is the full film lubrication zone where two contact surfaces are completely separated by a lubricant film and the other one is the asperity contact zone with direct metal-tometal contact. Therefore, in order to obtain more reasonable results, the time-varying friction coefficient in the mixed lubrication condition is analyzed. The tooth meshing friction coefficient can be represented by

$$
\mu^{\mathrm{ML}}=\frac{F_{\text {total }}}{P_{\text {total }}} .
$$

The total tangential load $F_{\text {total }}$ is consisted of full lubrication $\left(F_{\mathrm{EL}}\right)$ and asperity contact $\left(F_{\mathrm{BL}}\right)$, as

$$
F_{\text {total }}=F_{\mathrm{EL}}+F_{\mathrm{BL}}
$$

Likewise, the total normal contact load $P_{\text {total }}$ consists of full lubrication $\left(P_{\mathrm{EL}}\right)$ and asperity contact $\left(P_{\mathrm{BL}}\right)$, as

$$
P_{\text {total }}=P_{\mathrm{EL}}+P_{\mathrm{BL}}
$$

It may be noted that the load share coefficient of full lubrication is $f_{\lambda}\left(0 \leqslant f_{\lambda} \leqslant 1\right)$. Thus, the load share coefficient of asperity contact is $1-f_{\lambda}$. Then, it can be shown as

$$
\begin{aligned}
& P_{\mathrm{EL}}=P_{\text {total }} f_{\lambda} \\
& P_{\mathrm{BL}}=P_{\text {total }}\left(1-f_{\lambda}\right) .
\end{aligned}
$$


Likewise, similar to the normal contact load component, the tangential load can be written as

$$
\begin{aligned}
& F_{\mathrm{EL}}=\mu^{\mathrm{EL}} P_{\mathrm{EL}}=\mu^{\mathrm{EL}} P_{\text {total }} f_{\lambda} \\
& F_{\mathrm{BL}}=\mu^{\mathrm{BL}} P_{\mathrm{BL}}=\mu^{\mathrm{BL}} P_{\text {total }}\left(1-f_{\lambda}\right),
\end{aligned}
$$

where $\mu^{\mathrm{EL}}$ is the friction coefficient of full film lubrication and $\mu^{\mathrm{BL}}$ is the friction coefficient of asperity contact. In addition, Winter and Michaelis [17] proposed an important relation between the average friction coefficient and the instantaneous friction coefficient under the state of full film lubrication, as shown below:

$$
\mu^{\mathrm{EL}}=\mu_{i}^{\mathrm{EL}}\left(f_{\lambda}\right)^{0.2} .
$$

Thus, (7) can be written as

$$
\mu_{i}^{\mathrm{ML}}=\mu_{i}^{\mathrm{EL}}\left(f_{\lambda}\right)^{1.2}+\mu_{i}^{\mathrm{BL}}\left(1-f_{\lambda}\right) .
$$

Zhu and Hu [18] and Castro and Seabra [19] proposed the following definition of the load share function for point contacts given by

$$
\begin{aligned}
& f_{\lambda, \text { zhu }}=\frac{1.21 \lambda^{0.64}}{1+0.37 \lambda^{1.26}} \\
& f_{\lambda, \text { zhu }}=0.82 \lambda^{0.28},
\end{aligned}
$$

where $\lambda$ is defined as the ratio of the average oil film thickness lubricant to the root-mean square of surface roughness.

Also, $\lambda$ is an important indicator to distinguish the lubrication state. Based on the research of Castro and Seabra [14], the film thickness ratio between $0.36 \leqq \lambda \leqq 1.8$ is thought to be a state of mixed film lubrication. In the mixed lubrication zone, the load share coefficient of full lubrication $f_{\lambda}$ increases with the increase of $\lambda$, until it reaches a state of full film lubrication. For our calculation, a simplified value for the film thickness ratio 1.08 was used.

The instantaneous friction coefficient in mixed lubrication condition is determined by equation (14). The dynamic response of spiral bevel gear system considering the mixed lubrication time-varying friction coefficient can be calculated by substituting (14) into the dynamic model.

\section{Dynamic Response Analysis}

In this section, numerical integration applying the explicit 4/5th order Runge-Kutta formula is used to solve the nonlinear dynamic model. And the gear dynamic responses including dynamic mesh force and dynamic transmission error were computed and analyzed. The analysis compares the dynamic responses of the original and improved spiral bevel gears. The main geometry parameters are shown in Table 4 . The dynamic mesh force and dynamic transmission error are shown in Figures 3 and 4.

From Figure 3, it can be seen that little differences of the dynamic mesh force between original spiral gears and improved spiral bevel gears can be observed for the frequency response up to $2000 \mathrm{~Hz}$. However, in this area the dynamic
TABLE 4: Design parameters of spiral bevel gear.

\begin{tabular}{lccc}
\hline & Pinion & & Wheel \\
\hline $\begin{array}{l}\text { Module } \\
\begin{array}{l}\text { Number of teeth } \\
\text { Helical angle }\end{array}\end{array}$ & 8 & 11 & \\
$\begin{array}{l}\text { Hand of spiral } \\
\text { Speed ratio }\end{array}$ & LH & 35 & 37 \\
\hline
\end{tabular}

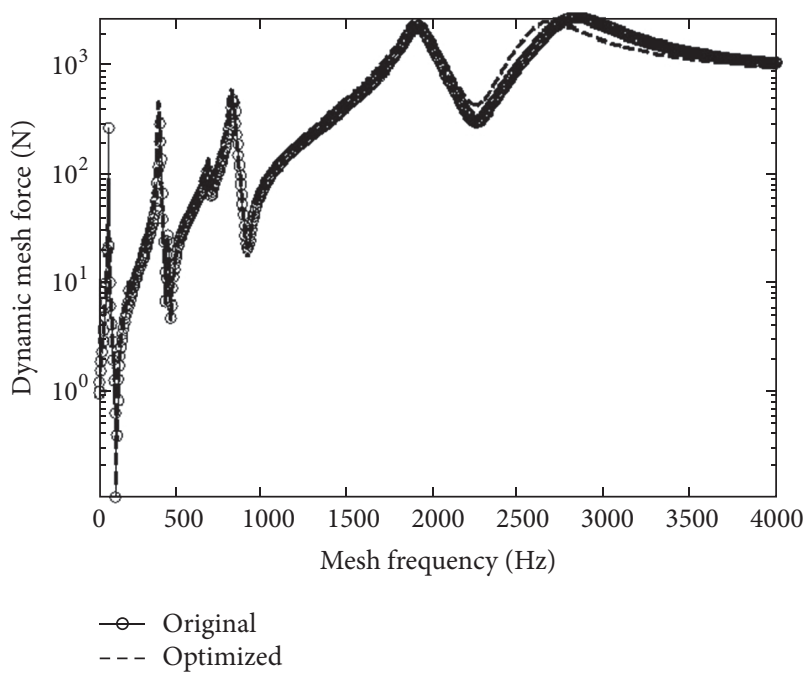

FIgURE 3: Dynamic mesh force response.

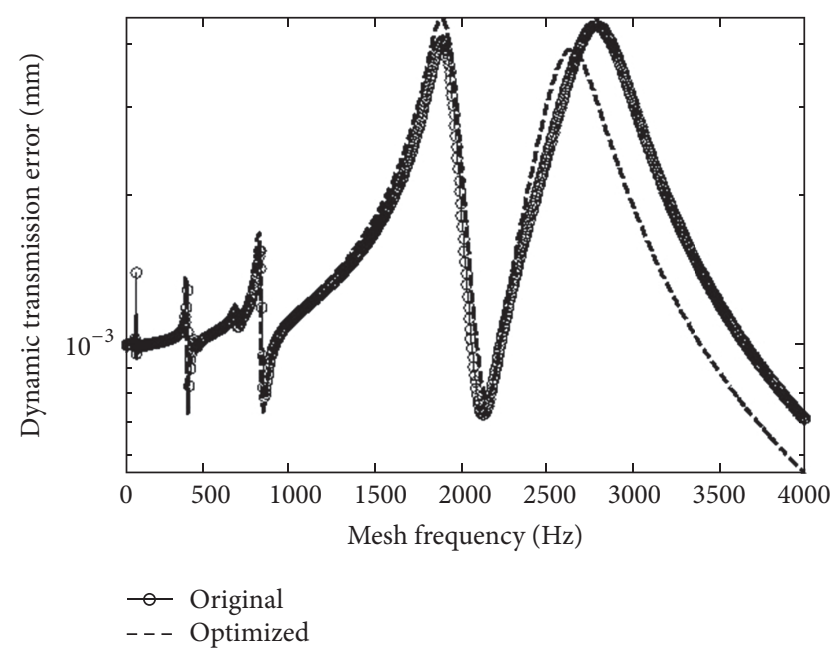

Figure 4: Dynamic transmission error.

mesh force has a relatively large amplitude and frequency fluctuations. The main reason is in the lower frequency zone; the variation range of friction coefficient is larger than that in the higher frequency range. In the frequency range from 2000 to $3500 \mathrm{~Hz}$, the improved gears have a lower maximum value and smaller fluctuation than the original design. On the other hand, for the dynamic transmission error as shown in Figure 4, the improved gears are obviously better in dynamic performance than the response of the original gears in the 


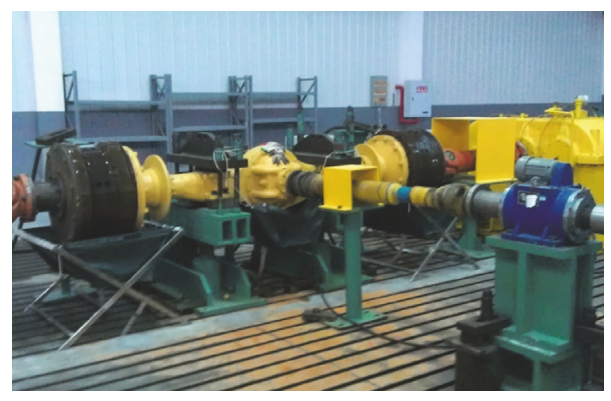

FIGURE 5: Bench testing setup.

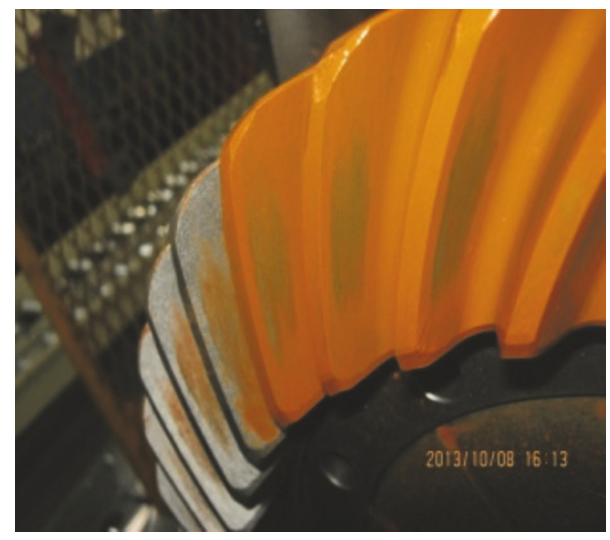

(a) Convex surface

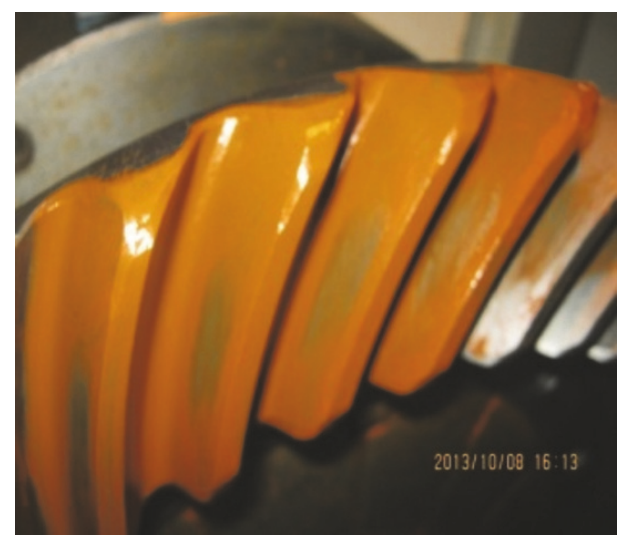

(b) Concave surface

Figure 6: Tested contact pattern for original design parameters.

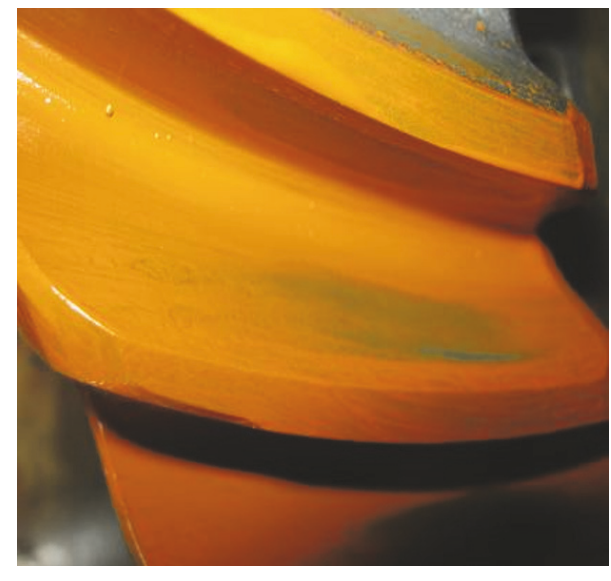

(a) Convex surface

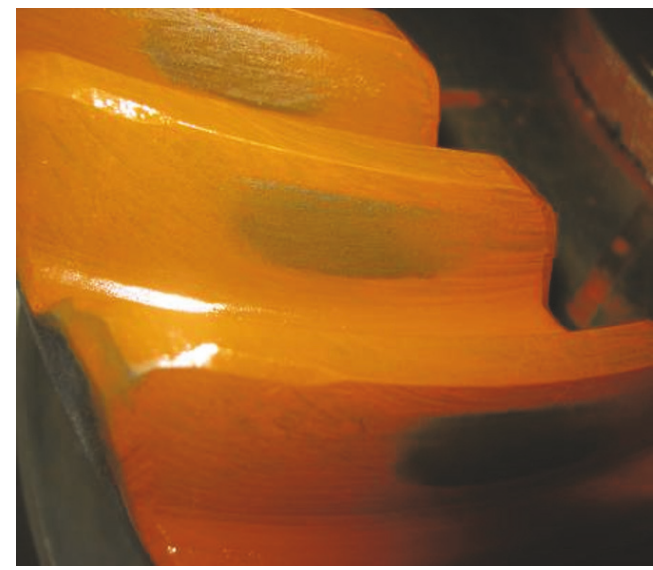

(b) Concave surface

FIGURE 7: Tested contact pattern for optimized design parameters.

frequency range from 2000 to $4000 \mathrm{~Hz}$. In practical application, the improvement of the dynamic responses indicates the reduction of the vibration and noise of gears.

\section{Bench Test}

Bench tests for both types of spiral bevel gears were conducted to verify the improvement of gears. The test rig is shown in Figure 5. The tested contact pattern for original and optimized design parameters underrated load condition are shown in Figures 6 and 7. The contact pattern is approximately located in the middle of the convex and concave tooth surface for the original geometry design parameters. But the location moved to the toe slightly for the optimized geometry design parameters which is better from the engineering view considering the actual load condition.

The bench test ran until the tooth fracture or serious pitting happened. Record running cycle times after the test 
TABLE 5: Results of the bench test.

\begin{tabular}{lccr}
\hline & Torque/N·m & Cycles/10 & Failure mode \\
\hline \multirow{2}{*}{ Original } & & 42.2 & Pinion teeth fracture \\
& \multirow{2}{*}{110367} & 31.5 & Pinion teeth fracture \\
& & 26.38 & Wheel teeth fracture \\
\hline \multirow{3}{*}{ Optimized } & \multirow{2}{*}{110367} & 53.5 & Pinion pitting \\
& & 40.8 & Wheel teeth fracture \\
& & 49.34 & Wheel teeth fracture \\
\hline
\end{tabular}

finish. The test results are shown in Table 5. It can be seen that the average number of cycles for original spiral bevel gears is 333,600 . And the average number of cycles for improved spiral bevel gear is 478,800 , which is an increase by $44 \%$ compared to the original gears.

\section{Conclusions}

(1) A quasi-static mesh model of spiral bevel gears was established and the effects of main geometry parameters on the contact and bending strength were investigated. Higher value for the pressure angle, root fillet radius, and the ratio of tooth thickness tend to improve the contact and bending strength and to reduce the risk of tooth fracture.

(2) The dynamic analysis of original and improved spiral bevel gears applying the lumped parameter dynamic model and the theory of mixed elastohydrodynamic lubrication was performed. The results indicate that improved gears have a better vibration performance in the targeted frequency range.

(3) Bench tests for both types of spiral bevel gears were performed. Results show that the main failure mode is the tooth fracture and the life was increased a lot for the spiral bevel gears with improved geometry parameters compared to the original design.

\section{Conflicts of Interest}

The authors declare that they have no conflicts of interest.

\section{Acknowledgments}

The authors would like to thank the National Natural Science Foundation of China (Grant no. 51405043), China Postdoctoral Science Foundation (Grant no. 2015M582517), Chongqing Research Program of Basic Research and Frontier Technology (no. cstc2016jcyjA0415), Postdoctoral Special Projects Funded of Chongqing (no. Xm2016004), Fundamental Research Funds for Central Universities (106112017CDJPT280002), and the support by Driveline R\&D of Liugong. Also, thanks are due to Professor Teik C. Lim (College of Engineering and Applied Science at the University of Cincinnati).

\section{References}

[1] Y. J. Zhao and K. Dong, "Mechanical performance of involute spur gear with 28 degrees pressure angle," Journal of Mechanical Transmission, vol. 28, no. 1, pp. 52-53, 2004.
[2] J. L. Huang, X. X. Miu, and S. M. Luo, "Influence analysis on the elasto hydrodynamic lubrication affected by pressure angle of gear," Journal of Machine Design, vol. 23, no. 12, pp. 14-15, 2006.

[3] Q. Fan, "Tooth surface error correction for face-hobbed hypoid gears," Journal of Mechanical Design, Transactions of the ASME, vol. 132, no. 1, pp. 0110041-0110048, 2010.

[4] Q. Fan, "Optimization of face cone element for spiral bevel and hypoid gears," Journal of Mechanical Design, Transactions of the ASME, vol. 133, no. 9, Article ID 091002, 2011.

[5] M. Kolivand and A. Kahraman, "An ease-off based method for loaded tooth contact analysis of hypoid gears having local and global surface deviations," Journal of Mechanical Design, Transactions of the ASME, vol. 132, no. 7, pp. 0710041-0710048, 2010.

[6] M. A. Hotait, A. Kahraman, and T. Nishino, "An investigation of root stresses of hypoid gears with misalignments," Journal of Mechanical Design, Transactions of the ASME, vol. 133, no. 7, Article ID 071006, 2011.

[7] Y. Yang, S. Mao, W. Guo, and Y. Kuang, "Pinion development of face-milled spiral bevel and hypoid gears based on contact attributes," International Journal of Advanced Manufacturing Technology, vol. 84, no. 9-12, pp. 2347-2356, 2016.

[8] K. Kawasaki, I. Tsuji, H. Gunbara, and H. Houjoh, "Method for remanufacturing large-sized skew bevel gears using $\mathrm{CNC}$ machining center," Mechanism and Machine Theory, vol. 92, article no. 2504, pp. 213-229, 2015.

[9] R. Tan, B. Chen, C. Peng, and X. Li, "Study on spatial curve meshing and its application for logarithmic spiral bevel gears," Mechanism and Machine Theory, vol. 86, pp. 172-190, 2015.

[10] V.Simon, "Head-cutter for optimal tooth modifications in spiral bevel gears," Mechanism and Machine Theory, vol. 44, no. 7, pp. 1420-1435, 2009.

[11] V. V. Simon, "Optimal machine-tool settings for the manufacture of face-hobbed spiral bevel gears," Journal of Mechanical Design, Transactions of the ASME, vol. 136, no. 8, Article ID 081004, 2014.

[12] J. Yang and T. C. Lim, "Influence of propeller shaft bending vibration on drivetrain gear dynamics," International Journal of Automotive Technology, vol. 16, no. 1, pp. 57-65, 2015.

[13] T. Peng, Coupled multi-body dynamic and vibration analysis of hypoid and bevel geared rotor system [Ph.D. thesis], University of Cincinnati, Ph.D. Dissertation, Cincinnati, OH, USA, 2010.

[14] Z. Feng, Research on multi-body muti-DOF nonlinear dynamic of helical bevel gear [Ph.D. thesis], Chongqing University, Ph.D. Dissertation, Chongqing, China, 2010.

[15] Z. Feng, S. Wang, T. C. Lim, and T. Peng, "Enhanced friction model for high-speed right-angle gear dynamics," Journal of Mechanical Science and Technology, vol. 25, no. 11, pp. 2741-2753, 2011. 
[16] S. Wang, Z. Feng, S. Lei, and H. Xiao, "Effect of time-varying friction coefficient on dynamics of spiral bevel gears," China Mechanical Engineering, vol. 22, no. 2, pp. 148-152, 2011.

[17] H. Winter and K. Michaelis, "Scoring load capacity of gears lubricated with EP-oils," Tech. Rep., AGMA Fall Technical Meeting, Montreal, Canada, 1983.

[18] D. Zhu and Y.-Z. Hu, "A computer program package for the prediction of EHL and mixed lubrication characteristics, friction, subsurface stresses and flash temperatures based on measured 3-D surface roughness," Tribology Transactions, vol. 44, no. 3, pp. 383-390, 2001.

[19] J. Castro and J. Seabra, "Coefficient of friction in mixed film lubrication: gears versus twin-discs," Proceedings of the Institution of Mechanical Engineers, Part J: Journal of Engineering Tribology, vol. 221, no. 3, pp. 399-411, 2007. 


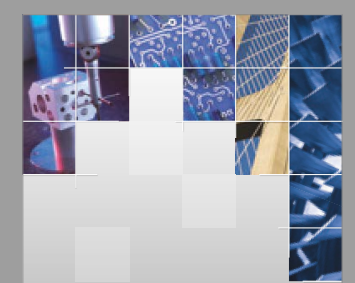

\section{Enfincering}
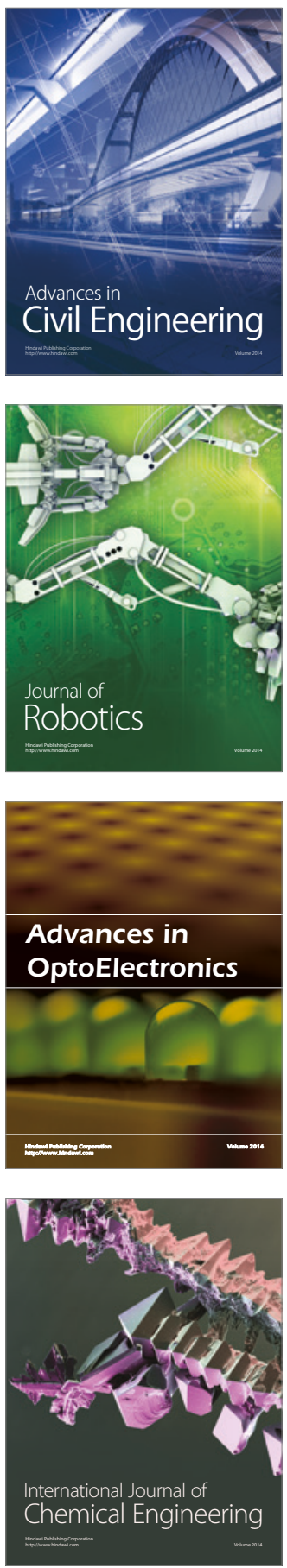

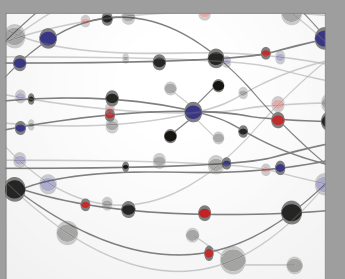

The Scientific World Journal

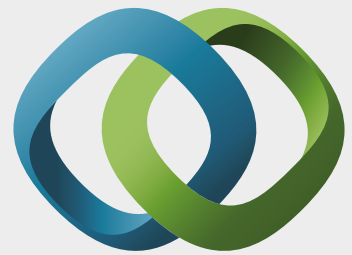

\section{Hindawi}

Submit your manuscripts at

https://www.hindawi.com
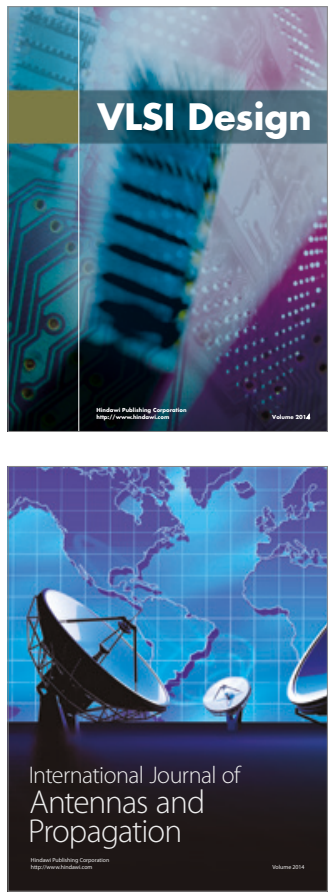

\section{Rotating}

Machinery
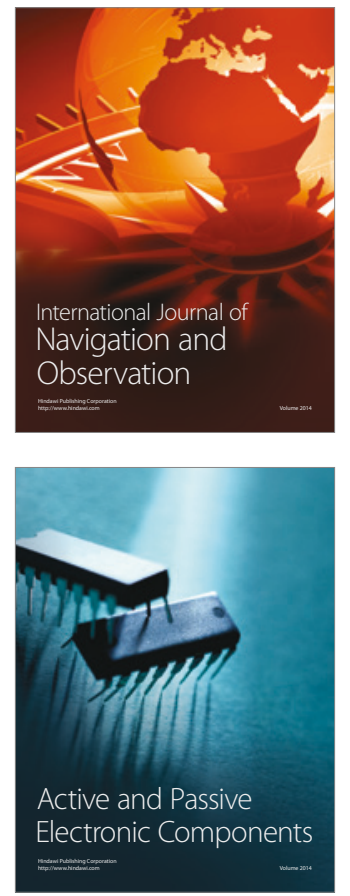
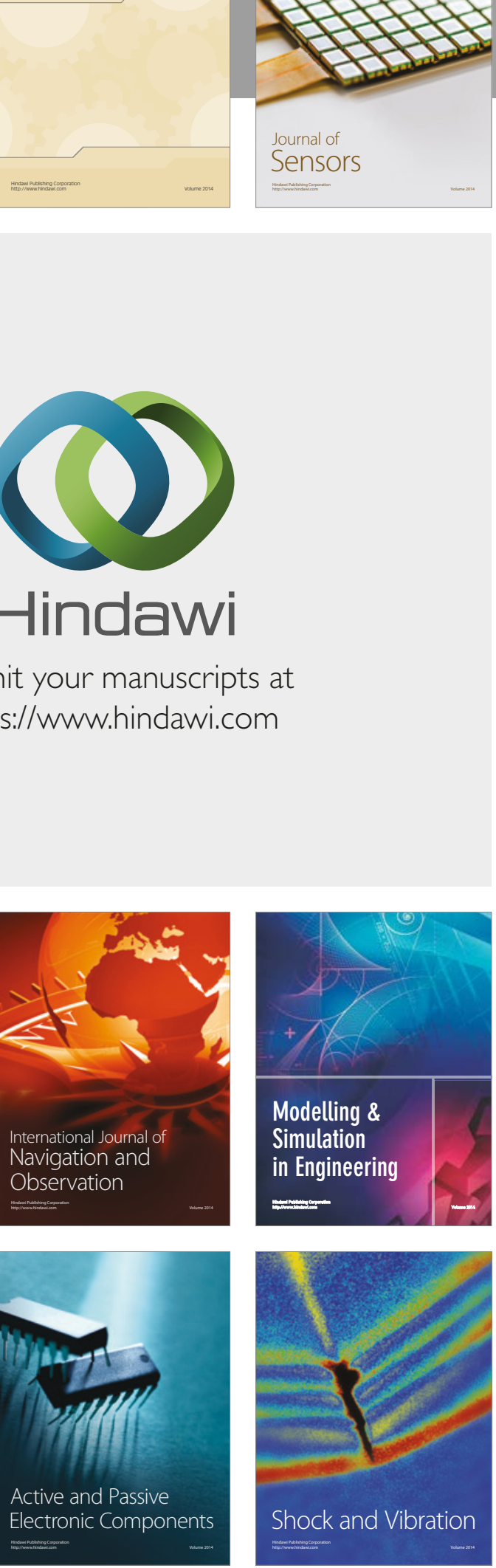
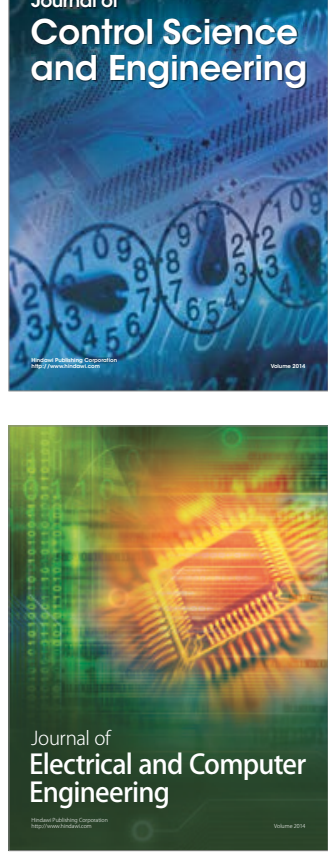

Distributed

Journal of

Control Science

and Engineering
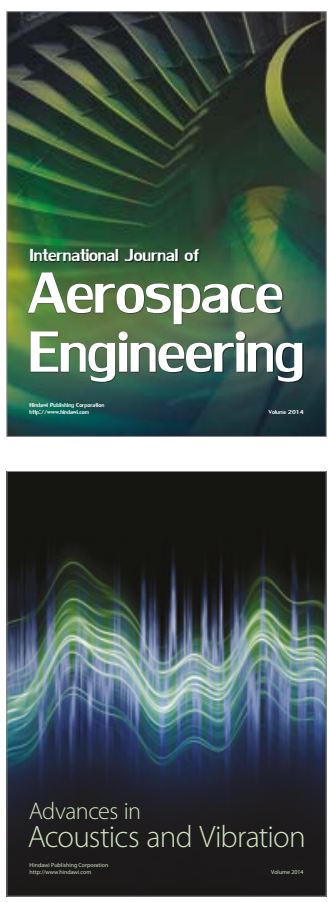

Sensor Networks 